\title{
Inpatients' satisfaction toward nursing services in the medical and surgical wards of Rizgary Teaching Hospital, Erbil, Iraq
}

\begin{abstract}
Namir Ghanim Al-Tawil * $\quad$ Ibrahim Hassan Mustafa ** $\quad$ Zhyan Abdullah Ismahil **
\section{Abstract}

Background and objective: Patients' satisfaction toward nursing care is an important indicator of the quality of nursing services. This study aimed to assess patients' satisfaction with nursing services provided in Rizgary Teaching Hospital and to find out the factors that are associated with levels of satisfaction.

Methods: A cross-sectional study was conducted in Rizgary Teaching Hospital in Erbil city, starting from January $17^{\text {th }}, 2014$ to March $11^{\text {th }}, 2015$. A convenience sampling method was used to recruit 200 patients (100 males and 100 females) from medical and surgical wards. Patients aged $\geq 15$ years, who were admitted to medical and surgical wards for $\geq 48$ hours were included. A structured questionnaire designed by researchers was completed through direct interview. Chi-square test of association (or Fisher's exact test) was used to compare proportions. A $P$ value of $\leq 0.05$ was considered as statistically significant.

Results: The study showed that $40.5 \%$ of patients were highly satisfied with the nursing services, only $20.9 \%$ of those with secondary education or higher were highly satisfied $(P=0.005)$, and $80 \%$ of those with high income were highly satisfied $(P=0.001)$. There was no significant association between patients' satisfaction and patients' age, marital status, occupation, residence, the length of stay, and type of ward. A relatively poor rate of satisfaction $(20.5 \%)$ was observed regarding the information provided by nurses before the medical care or drug administration.
\end{abstract}

Conclusions: Less educated patients were more satisfied with nursing services. The majority of patients were unsatisfied with the information provided by nurses before medical care or drug administration.

Keywords: Patients satisfaction; Nursing health services; Iraq; Erbil.

\section{Introduction}

Nurses spend a lot of time and are in closer contact with patients than other health care professionals. ${ }^{1}$ Patients' perception regarding the quality of nursing services is an important measure of assessing the quality of nursing health care..$^{2-4}$ Therefore, dissatisfaction with the nursing care services may further lead to lower utilization of the nursing services by the patients. ${ }^{5}$ Satisfaction, like many other psychological concepts, is easy to understand but hard to define. The concept of satisfaction overlaps with similar terms such as happiness, contentment, and quality of life. Patients' satisfaction is a result of accumulation of people's experience over time toward health services. ${ }^{6}$ Patients' satisfaction toward nursing services can be defined as the degree of congruence between patients' experience and expectations of ideal services and the actual services provided by nurses. ${ }^{7,8}$ The desired need for the measurement of patient satisfaction has been largely driven by the underlying politics of "new public management". Important factors influencing patients/ clients satisfaction toward nursing services include literacy levels, intellectual and physical/sensory disability levels and difficulties with language proficiency or

* Department of Community Medicine, College of Medicine, Hawler Medical University, Erbil, Iraq.

** Department of Nursing, College of Nursing, Hawler Medical University, Erbil, Iraq. 
ethnic and cultural diversity. ${ }^{6}$ Up to researchers' knowledge, no previous study had been carried out in Erbil to assess the inpatients' satisfaction toward nursing services provided in the hospitals. This study aimed to assess patients' satisfaction with nursing care provided in Rizgary Teaching Hospital and find out the factors that are associated with higher levels of satisfaction.

\section{Methods}

A cross-sectional study was conducted in Rizgary Teaching Hospital in Erbil city, starting from January $17^{\text {th }}, 2014$ to March $11^{\text {th }}$, 2015. A convenience method of sampling was used to recruit 200 patients from medical and surgical wards (100 males and 100 females). Inclusion criteria were patients who were admitted to the medical and surgical wards during the study period, of both genders, aged 15 years or more. Exclusion criteria were unconscious patients and patients who had less than 48 hours duration of stay in the hospital. A direct interview was conducted with the patients, using a questionnaire designed by the researchers. The questionnaire consisted of two parts; part one related to sociodemographic characteristics of patients (such as age, gender, marital status, occupation, levels of education, address, and levels of income) and hospitalization data (such as the type of the ward and the duration of hospital stay). Part two involved a number of questions about nursing care. A five points Likert scale was used to assess patients' satisfaction, where score five indicated the highest level of satisfaction and score 1 indicated the lowest level of satisfaction. Patients were asked 15 questions to assess their satisfaction with nursing care. The total score was then divided into three categories (25 scores for each): low ( $\leq 25)$, medium (26-50), and high (51-75) level of satisfaction.

Statistical analysis:

The statistical package for the social sciences (SPSS, version 19) was used for data entry and analysis. Chi-square test of association was used to compare proportions. Fisher's exact test was used instead of Chi-square test when the expected count of more than $20 \%$ of the cells of the table was less than 5 . A $P$ value of $\leq 0.05$ was considered as statistically significant.

\section{Results}

The mean age of the study sample $( \pm S D)$ was $43.73 \pm 19.27$ years ranging from $15-82$ years. Table 1 shows that $42 \%$ of the study sample were aged 50 years and above; while $27.5 \%$ were less than 30 years old. The table shows that $30 \%$ of the study sample was illiterate. More than two-thirds of the study sample $(70.5 \%)$ were married. The same table shows that $65.5 \%$ of the sample was unemployed (including housewives). Regarding income, $46.5 \%$ of patients did not have adequate income for daily living, and $62 \%$ were living in an urban area. 
Inpatients' satisfaction toward nursing services .......

Table 1: Socio-demographic characteristics of the study sample.

Variables No.

No.

(\%)

\section{Age}

$<30$

55

30-39

40-49

$50-59$

$60+$

\section{Education}

Illiterate 60

Read and write

27

Primary

20

Intermediate

41

Secondary

43

Institute and higher

Marital status

Married

Widowed

Divorced

Single

\section{Occupation}

Unemployed

Unskilled workers

Lower professionals

High professionals

Retired

Income

Not enough

93

Enough

92

Exceeds needs

15

Residency

Urban

Rural

76

200

Total 
Table 2 shows that $40.5 \%$ of the whole samples were very satisfied with the nursing services. High satisfaction was significantly lower among those with secondary education (20.9\%) and the graduates of institutes or colleges $(22.2 \%)$, $\mathrm{P}=0.005$. The table shows that $80 \%$ of those with high income (exceeding their daily needs) were highly satisfied with the nursing services compared with $30.1 \%$ among those with very low income $(P=0.001)$. No significant association was detected between other factors and the level of satisfaction.

Table 2: Level of satisfaction by socio-demographic characteristics of the studied sample.

\begin{tabular}{|c|c|c|c|c|}
\hline Variables & $\mathbf{N}$ & $\begin{array}{l}\text { Medium level of } \\
\text { satisfaction } \\
\text { No. (\%) }\end{array}$ & $\begin{array}{l}\text { High level of } \\
\text { satisfaction } \\
\text { No. (\%) }\end{array}$ & $P$ value \\
\hline \multicolumn{5}{|l|}{ Age } \\
\hline$<30$ & 55 & $32(58.2)$ & $23(41.8)$ & \multirow{5}{*}{0.959} \\
\hline $30-39$ & 32 & $18(56.3)$ & $14(43.8)$ & \\
\hline $40-49$ & 29 & $19(65.5)$ & $10(34.5)$ & \\
\hline $50-59$ & 23 & $14(60.9)$ & $9(39.1)$ & \\
\hline $60+$ & 61 & $36(59.0)$ & $25(41.0)$ & \\
\hline \multicolumn{5}{|l|}{ Educational level } \\
\hline Illiterate & 60 & $36(61.0)$ & $24(39.0)$ & \multirow{6}{*}{0.005} \\
\hline Read and write & 27 & $14(51.9)$ & $13(48.1)$ & \\
\hline Primary & 20 & $6(30.0)$ & $14(70.0)$ & \\
\hline Intermediate & 41 & $22(53.7)$ & $19(46.3)$ & \\
\hline Secondary & 43 & $34(79.1)$ & $9(20.9)$ & \\
\hline Institute and higher & 9 & $7(77.8)$ & $2(22.2)$ & \\
\hline \multicolumn{5}{|l|}{ Marital status } \\
\hline Married & 141 & $80(56.7)$ & $61(43.3)$ & \multirow{4}{*}{0.313} \\
\hline Widowed & 7 & $4(57.1)$ & $3(42.9)$ & \\
\hline Divorced & 4 & $4(100.0)$ & $0(0.0)$ & \\
\hline Single & 48 & $31(64.6)$ & $17(35.4)$ & \\
\hline \multicolumn{5}{|l|}{ Occupation } \\
\hline Unemployed & 131 & $82(62.6)$ & $49(37.4)$ & \multirow{5}{*}{0.606} \\
\hline Unskilled workers & 18 & $8(44.4)$ & $10(55.6)$ & \\
\hline Lower professionals & 34 & $20(58.8)$ & $14(41.2)$ & \\
\hline High professionals & 2 & $1(50.0)$ & $1(50.0)$ & \\
\hline Retired & 15 & $8(53.3)$ & $7(46.7)$ & \\
\hline \multicolumn{5}{|l|}{ Level of income } \\
\hline Not enough & 93 & $65(69.9)$ & $28(30.1)$ & \multirow{3}{*}{0.001} \\
\hline Enough & 92 & $51(55.4)$ & $41(44.6)$ & \\
\hline Exceed needs & 15 & $3(20.0)$ & $12(80.0)$ & \\
\hline \multicolumn{5}{|l|}{ Residency } \\
\hline Urban & 124 & $70(56.5)$ & $54(43.5)$ & \multirow{3}{*}{0.262} \\
\hline Rural & 76 & $49(64.5)$ & $27(35.5)$ & \\
\hline Total & 200 & 119 (59.5) & $81(40.5)$ & \\
\hline
\end{tabular}


There was no statistically significant difference between surgical and medical wards regarding levels of satisfaction $(P=0.356)$ although $37.7 \%$ of those who had been admitted to the medical ward scored high level of satisfaction compared with $44.2 \%$ in surgical wards (Table 3 ). The same table shows no significant association between the period of stay and the level of satisfaction. Overall, $49.5 \%$ of the sample had high scores of satisfaction
( 4 or 5$)$. The majority of the sample $(81 \%)$ were very satisfied with the uniform of nurses, and their availability day round, $57.5 \%$ were high satisfied (score 4 or 5 ) about nurses' willingness to answer patients' questions. Only 20.5\% were highly satisfied (scores 4 or 5) with the information given by nurses when providing medical care, including drugs administration (Table 4).

Table 3: Level of satisfaction by type of ward and length of stay

\begin{tabular}{lcccc}
\hline Variables & $N$ & $\begin{array}{l}\text { Medium level of satisfaction } \\
\text { No. }\end{array}$ & $\begin{array}{l}\text { High level of satisfaction } \\
\text { No. }\end{array}$ & (\%) \\
\hline Admission ward & 114 & $71(62.3)$ & $43(37.7)$ & 0.356 \\
$\begin{array}{l}\text { Medicine } \\
\text { Surgery }\end{array}$ & 86 & $48(55.8)$ & $38(44.2)$ & \\
Length of hospital stay (days) & 128 & & & \\
$<4$ & 51 & $82(64.1)$ & $46(35.9)$ & 0.197 \\
$4-6$ & 21 & $27(52.9)$ & $24(47.1)$ & \\
$7+$ & $10(47.6)$ & $11(52.4)$ & \\
\hline
\end{tabular}

Table 4: Distribution of the sample according to levels of satisfaction with specific nursing services

\begin{tabular}{|c|c|c|c|c|c|}
\hline \multirow[b]{2}{*}{ Items } & \multicolumn{5}{|c|}{ Levels of satisfaction } \\
\hline & $\begin{array}{l}\text { Very } \\
\text { poor } \\
\text { No. }(\%)\end{array}$ & $\begin{array}{l}\text { Poor } \\
\text { No. (\%) }\end{array}$ & $\begin{array}{l}\text { Fair } \\
\text { No. }(\%)\end{array}$ & $\begin{array}{l}\text { Good } \\
\text { No. }(\%)\end{array}$ & $\begin{array}{l}\text { Very } \\
\text { good } \\
\text { No. (\%) }\end{array}$ \\
\hline Welcomed you with a smiling face & $3(1.5)$ & $3(1.5)$ & $67(33.5)$ & $100(50.0)$ & $27(13.5)$ \\
\hline The uniform of nurses is elegant & $2(1.0)$ & $3(1.5)$ & $33(16.5)$ & $98(49.0)$ & $64(32.0)$ \\
\hline Satisfaction with admission process & $0(0.0)$ & $8(4.0)$ & $84(42.0)$ & $78(39.0)$ & $30(15.0)$ \\
\hline On-call nurses are available & $3(1.5)$ & $2(1.0)$ & $33(16.5)$ & $119(59.5)$ & $43(21.5)$ \\
\hline Nurses are willing to help you at all time & $0(0.0)$ & $5(2.5)$ & $53(26.5)$ & $120(60.0)$ & $22(11.0)$ \\
\hline Nurses visit you at regular times & $8(4.0)$ & $6(3.0)$ & $74(37.0)$ & $83(41.5)$ & $29(14.5)$ \\
\hline $\begin{array}{l}\text { Nurses provide a clear explanation } \\
\text { (information) before giving medical care } \\
\text { (including drugs) }\end{array}$ & $42(21.0)$ & $40(20.0)$ & $77(38.5)$ & $31(15.5)$ & $10(5.0)$ \\
\hline $\begin{array}{l}\text { Welcoming relatives during visiting patients in } \\
\text { the hospital }\end{array}$ & $12(6.0)$ & $23(11.5)$ & 106(53.0) & $46(23.0)$ & $13(6.5)$ \\
\hline listening to patients worry with patience & $10(5.0)$ & $24(12.0)$ & $103(51.5)$ & $47(23.5)$ & $16(8.0)$ \\
\hline Nurses are willing to answer your questions & $2(1.0)$ & $13(6.5)$ & $70(35.0)$ & $100(50.0)$ & $15(7.5)$ \\
\hline $\begin{array}{l}\text { Nurses make patients feel safe and confident } \\
\text { when providing services }\end{array}$ & $4(2.0)$ & $33(16.5)$ & $101(50.5)$ & $40(20.0)$ & 22(11.0) \\
\hline Nurses make you feel at home & $9(4.5)$ & $69(34.5)$ & $80(40.0)$ & $25(12.5)$ & $17(8.5)$ \\
\hline The amount of privacy nurses gave you & $7(3.5)$ & $79(39.5)$ & $56(28.0)$ & $37(18.5)$ & $21(10.5)$ \\
\hline $\begin{array}{l}\text { The nurses explain things in a way you could } \\
\text { understand }\end{array}$ & $28(14.0)$ & $27(13.5)$ & $84(42.0)$ & $51(25.5)$ & $10(5.0)$ \\
\hline $\begin{array}{l}\text { Overall: how do you rate your satisfaction with } \\
\text { nursing services? }\end{array}$ & $2(1.0)$ & $4(2.0)$ & $95(47.5)$ & $64(32.0)$ & $35(17.5)$ \\
\hline
\end{tabular}




\section{Discussion}

The results of this study showed a significant association between low educational levels of the study participants and the high rates of satisfaction. This could be attributed to the lower expectations of people with low level of education toward the nursing services, as they may not know the ideal status of services, and think that what they received is the best that can be offered. A study done in a surgical ward of a general hospital in Greece by Giannakopoulou et al. in 2011, involving 93 inpatients, showed high rates of satisfaction, knowing that the majority of the studied sample had low educational levels. ${ }^{10}$ This study indicates that the more the income, the more the satisfaction. In contrast with a study done by Pascoe in 1983, which showed that high income among patients is a factor for less satisfaction toward nursing services. ${ }^{11}$ While two studies were done in Iran by Akhtari-Zavare et al. and Sadjadian et al. indicated that there was no relationship between the level of satisfaction and income. $^{12,13}$ The inconsistency in results of this study and the results of other studies could be attributed to the fact that income is subjective and participants could be erroneously classified into different income categories. The present study indicated that there was no association between age and level of satisfaction. It agrees with a study done by Tang et al. in Federal Territory of Kuala Lumpur, Malaysia in 2013 which indicated that there was no significant association between age of patients and level of patients' satisfaction toward nursing services. ${ }^{14}$ The study indicates that more than half $(65.5 \%)$ of the study sample were unemployed, among them, $62.6 \%$ were in medium levels of satisfaction, there was no association between occupational classes and levels of satisfaction. This was contrary to a previous study conducted in China by Liu and Wang that involved 320 patients. Results indicated that patients' occupation is one of the main factors influencing their satisfaction with nursing care. ${ }^{15}$ Our results indicated that there was no association between levels of satisfaction and type of the wards. This could be attributed to the fact that nurses in medical and surgical wards are of the same background and are randomly assigned to work in medical and surgical wards. Whereas, a study conducted by Senarath et al. in National Hospital of Sri Lanka showed that satisfaction was low in a medical ward compared with a surgical ward. ${ }^{16}$ This study showed no significant association between length of stay in hospital and levels of patients' satisfaction. This coincides with results of a study conducted among 110 orthopedic patients in Malaysia, which showed that there was no association between the period of stay and patients' satisfaction. ${ }^{17}$ However, Findik et al. showed in a study conducted in a tertiary care hospital in Turkey that the satisfaction rates increase with the long period of stay in the hospital. ${ }^{18}$ Table 4 showed that $71 \%$ and $81 \%$ of the study sample showed high levels of satisfaction (score 4 and 5) about "nurse willing to help patients at any time" and "nurses are available on call", respectively. This indicates that nurses were available day round and nurses were ready to help patients at any time during all shifts. In contrast with a study conducted by Dzomeku et al. 2012 in Kwame Nkrumah University of Science and Technology (KNUST) hospital. $^{19}$ A relatively poor rate of satisfaction $(20.5 \%)$ was found regarding the information provided by nurses before the medical care or drug administration. A lower rate was detected in a study done by Bilkish et al. during $2010 .^{20}$ It showed that $13.3 \%$ of patients attending the outpatient clinic of a general hospital received detailed information from nurses about treatment use just before receiving the treatment. This study is limited by having a non-randomly selected sample. However, the researchers recruited the patients haphazardly during their availability in the hospitals. 
http://dx.doi.org/10.15218/zjms.2016.0030

Asking the patients about their real income was embarrassing, so they were asked whether the income is enough, not enough, or exceeds the need which is more or less subjective.

\section{Conclusions}

A considerable proportion of patients were highly satisfied with nursing care, and higher levels of satisfaction were found among the less educated patients.

\section{Conflicts of interest}

The authors report no conflicts of interest.

\section{References}

1. Walsh M, Walsh A. Measuring patient satisfaction with nursing care: Experience of using the Newcastle Satisfaction with Nursing Scale. JAN 1999; 29(2):307-15.

2. Donabedian $A$. The quality of care. How can it be assessed? JAMA 1988; 260(12):1743-8.

3. Aiell A, Garman A, Morris BS. Patient satisfaction with nursing care: A multilevel analysis. Qual Manag Health Care 2003; 12 (3):187-91.

4. Mrayyan MT. Jordanian nurses' job satisfaction, patients' satisfaction and quality of nursing care. International Nursing Review 2006; 53:224-30.

5. Yunus MA, Nasir MT, Nor Afiah MZ, Sherina MS, Faizah MZ. Patient satisfaction: a comparison between government and private clinics in Mukim Labu, Sepang, Selangor. MJPHM 2004; 4(2):6-11.

6. Doherty D. Measurement of Patient Satisfaction Guidelines Health Strategy Implementation Project 2003. The Health Board Executive. (Accessed on June 26 ${ }^{\text {th }}$, at http://hdl.handle.net/10147/43559)

7. Merkouris A, Papathanassoglou ED, Lemonidou C. Evaluation of patient satisfaction with nursing care: quantitative or qualitative approach? Int J Nurs Stud 2004; 41:355-67.

8. Swartz TA, Bowen DE, Brown SN. Hand book of services marketing and management advances in service marketing and management; 2000. PP. 65-85.

9. Hood C. The new public management in the 1980s: variations on a theme. J Account Organ Soc 1995; 20(2-3):93-109.

10. Giannakopoulou G, Tsironi M, Prezerakos P, Fotis T, Giannakopoulou E, Zyga S. Surgical patient satisfaction: nursing care quality index. Helenic Journal of Nursing Studies 2012; 5(1): 14-20,

11. Pascoe GC. Patient satisfaction in primary health care: a literature review and analysis. Eval Prog Plan 1983; 6:185-210.

12. Akhtari-Zavare M, Abdullah MY, Syed Hassan S, Said SB, Kamali M. Patient Satisfaction:
Evaluating Nursing Care for Patients Hospitalized with Cancer in Tehran Teaching Hospitals, Iran. Global Journal of Health Science 2010; 2(1):117 -26 .

13. Sadjadian A, Kaviani A, Yunesian M, Montazeri A. Patient satisfaction: a descriptive study of a breast care clinic in Iran. Eur J Cancer Care 2004; 13(2):163-8.

14. Tang WM, Soong C, Lim W. Patient satisfaction with nursing care: A descriptive study using interaction model of client health behavior. Int $\mathrm{J}$ Nurs Sci 2013; 3(2):51-61.

15. Liu Y, Wang G. Inpatient satisfaction with nursing care and factors influencing satisfaction in a teaching hospital in China. J Nurs Care Qual 2007; 22(3):266-71.

16. Senarath U, Gunawardena NS, Sebastiampillai B, Senanayake A, Lekamge S, Seneviratna A, et al. Patient satisfaction with nursing care and related hospital services at the National Hospital of Sri Lanka. J Leadersh Health Serv 2013; 26 (1):63-77.

17. Teng KY, Norazliah S. Surgical Patients' Satisfaction of Nursing Care at the Orthopedic Wards in Hospital Universiti Sains Malaysia. Health Environment J 2012; 3(1):36-43.

18. Findik UY, Unsar S, Sut N. Patient satisfaction with nursing care and its relationship with patient characteristics. Nurs Health Sci 2010; 12(2): 162-9.

19. Dzomeku VM, Ba-Etilayoo A, Perekuu T, Mantey RE. In-patient satisfaction with nursing care: A case study at Kwame Nkrumah University of Science and Technology Hospital. International Journal of Research in Medical and Health Sciences 2013; 2(1):19-24.

20. Bilkish P, Sangita S, Prakash A, Manjunath K. A cross-sectional study of patient's satisfaction towards services received at tertiary care hospital on OPD basis. Nat J Community Med 2012; 3(2):232-7. 